University of Nebraska - Lincoln

DigitalCommons@University of Nebraska - Lincoln

Publications of the Research Compliance

Services Staff

Research Compliance Services

June 2006

\title{
Resisting Power and Influence: A Case Study in Virtue Ethics
}

Daniel R. Vasgird

University of Nebraska - Lincoln, dvasgird2@unl.edu

Follow this and additional works at: https://digitalcommons.unl.edu/researchcompsvcspubs

Part of the Higher Education Administration Commons

Vasgird, Daniel R., "Resisting Power and Influence: A Case Study in Virtue Ethics" (2006). Publications of the Research Compliance Services Staff. 1.

https://digitalcommons.unl.edu/researchcompsvcspubs/1

This Article is brought to you for free and open access by the Research Compliance Services at DigitalCommons@University of Nebraska - Lincoln. It has been accepted for inclusion in Publications of the Research Compliance Services Staff by an authorized administrator of DigitalCommons@University of Nebraska - Lincoln. 


\section{Resisting Power and Influence: A Case Study in Virtue Ethics}

\author{
Daniel R. Vasgird \\ University of Nebraska-Lincoln
}

\begin{abstract}
This is a case study based on the author's experience while serving as an ethics committee (IRB) chair in New York City. It addresses the issues of power and coercion as they apply to the human research participants protection process. It primarily focuses on the power imbalance that can exist between research participants and their IRB advocates on the one hand and the research institutions, funding agencies, and investigators with their unlimited resources on the other. IRB Chairs and IRB leaders must be fire-walled from conflicts of interest arising not just from financial factors but from factors related to power, hierarchy, structure, and control. Senior staff, IRB members, administrators and ethicists best advocate for human volunteers in research through personal identification and solidarity.
\end{abstract}

Keywords: power, influence, hierarchy, control, IRB autonomy, advocacy

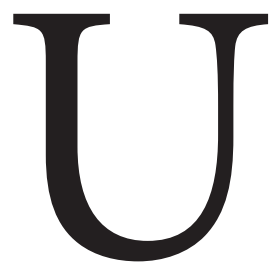

NTIL RECENTLY, I CHAIRED A FAIRLY HIGH volume, behavioral and biomedical sciences Institutional Review Board (IRB) for an institution in New York City that was centrally positioned for numerous collaborative national research investigations. About midway in my tenure there, a particularly sensitive and apparently risky joint protocol came before the Board from a principal investigator (PI) who was associated with a major research institution in our area. After I had designated that the protocol needed full board review, the PI, as requested, came and presented to the Board at a formal IRB meeting. Subsequently, an extensive dialogue ensued over how to properly address human research protections for this research, which seemed to offer the hope of significant benefit if conducted appropriately. With a better understanding of the complexity and implications of the research, the
Board decided to appoint an appropriate primary reviewer who did a substantial review of the literature in the subject area to assist in the risk/benefit analysis. After going over the primary reviewer's report, it was decided that several modifications and additions needed to be made in the proposed participant protection process. The Board considered it necessary to substantially raise the federal regulatory bar by requiring more than the minimum protections. The requested changes were delineated, explained, and sent on to the PI for compliance.

About a week later the PI phoned, asking if I would drop or weaken the stipulations, and I explained that the Board would not do that. In any event, I explained, I certainly did not have the authority to unilaterally counter the Board's wishes even if I wanted to. I told her she could prepare a response to the Board if she wished, which would be sent to them for review and discussion at the next meeting. She said her legal office, which had direct advisory responsibilities for all research compliance issues, would not allow her to make the changes requested. She said they were concerned about liability and institutional autonomy. After some discussion I realized the core concern was that the Board in this case had raised the regulatory bar beyond the federal minimum and stipulated that compensation in the event of medical injury would be required because of the very risky nature of the research. I ultimately replied that it would be unfortunate to not make the required changes since the research appeared to promise substantial benefit. She suggested that perhaps her legal counsel could be persuaded if they heard the explanation of our decision from me, so I agreed to meet with her and her counsel to discuss the matter.

A week later she called again asking if it might be possible for me to come by for an informal discussion about the protocol. I agreed and a few days later went to see them. When I walked into what I thought would be an office or a meeting room, I quickly realized it was the conference room adjoining the office 
of the president of the institution. Within a moment the president, general counsel, and PI walked into the room from his office, and I was smilingly introduced. After a minute of small talk, the general counsel jumped right in stating that it was unprecedented and impossible for them to comply with our requests, and that it was "arbitrary and capricious" for the IRB to ask for anything above and beyond the requirements of the federal regulations without formally putting it into our policies beforehand. I pointed out that our policies clearly state that the federal and state regulations are minimal standards, and that the IRB has the flexibility, discretion and empowerment to raise that bar as it feels necessary for each individual case. For this protocol the Board, acting as the participants' advocate, decided it was necessary to insist on greater protections for their well-being.

I then began to explain our reasoning for each stipulation. At that point, with no forewarning, the president interrupted and said that there was no need to discuss this further. I simply had to make the adjustments to fit their criteria. I said I would not do that and could not besides. In a split second his whole demeanor went from charm to a furious indignation. He looked at me and said he knew the person who headed my organization, and that he would have my "head on a plate" if I did not comply with their request. For the next five minutes or so, I sat in stunned disbelief while the president and the general counsel unloaded. When I regained my senses, I got up, said the Board's position was clear, excused myself and left.

Later that day, I reported what had happened to the head of my organization, who said it was hard to imagine since she knew the president to be "such a charming, witty and gracious person," but that a call would be made to remind him of the IRB's independent authority. In addition, I reported the incident back to the full IRB; they supported my actions without reservation. I did receive a follow-up phone call from the general counsel who said that perhaps the meeting did not go as smoothly as they would have preferred. My response was to say that that was totally of their making. When asked if I had given the protocol some further thought, I said that there was nothing to think about. I also pointed out that thankfully we had supportive organizational leadership, and in addition, I was protected by what was comparable to tenure. We never spoke again regarding the protocol. I heard from professional acquaintances that the general counsel had also approached OHRP for support and been told our IRB was perfectly within its rights and responsibilities. Over the next few months the PI submitted a series of revisions that ultimately complied with all of our original requests. In a nutshell, although I left the meeting that day trembling with anger, nothing changed for the PI or the protocol except for a lengthy delay in the approval process until the PI complied fully with the original stipulations.

\section{Lessons Learned}

I learned several lessons from this incident: First, never give up home-court advantage, i.e., all subsequent meetings with PIs and/or their advocates would take place in my office or our conference room. Second, I made it a point always to have our lawyer with me when chatting with those who ask if it is okay to have their lawyer sit in. There is no such thing as a conversation with benign intent when someone wants their lawyer nearby. This has carried through to my personal life as well. A third lesson that I have preached religiously since that day is that for the overall health and effectiveness of the human research protection system, organizations should insure that IRB chairs have tenure or something comparable. Chairing an IRB is not a job for a junior faculty member or the equivalent. I am glad I was able to stand up to a powerful and well-connected person in a challenging situation, but unfortunately it is not always the case that we have the luxury of security in those circumstances.

Sadly, the theme of this anecdote was not an isolated circumstance for me; it has presented itself, in different characters and guises, a number of times over the years. Sponsors, investigators or institutions in one way or another made veiled, or not so veiled, threats or perhaps more judiciously, disquieting suggestions.

\section{Overcoming the Empathic Divide}

I am a social psychologist by training, so you can guess perhaps that there is more of a point in this rendering than the very obvious lessons mentioned above. I want the reader to reflect on the empathetic divide that often exists between researchers, including those who support them, and the research participants, who are the foundation of their enterprise. This gulf exists even when there are the best of intentions. As a result, there can be considerable ambiguity about the motives of those investigators and gatekeepers who behave without due regard for the welfare of research participants.

For example, without proof to the contrary, I would agree with one commentator's assertion regarding the Johns Hopkins incident in which a research participant died as a direct result of the research in which she was participating. He said: "The issue is not inten- 
tional harm, but perhaps ignorance."1 Unless the ethics committee actively advocates for research participants, those responsible for harming participants are unlikely to be held to account. In the case I described here, if the IRB had allowed the study to run as originally presented, would the president have been accused of intentional harm had something gone amiss and the participant took the brunt of the consequences? Of course not. But can ignorance be a valid excuse when there is resistance to, or avoidance of, understanding the positions, vulnerabilities and needs of all those involved in the enterprises for which one is responsible? I would suggest that the president was not open to an explanation from me for the IRB's actions because neither empathetically nor in terms of accountability did he feel the need to hear such an account. I represented an entity outside of his realm of significant others. The research participant and the IRB were not relevant issues. His perceived constituency was limited to those to whom he was immediately accountable, and he knew their desires and objectives. Appropriately, though, the IRB also understood who its constituency was and was willing to assert itself. So this becomes a graphic example that it is only through an assertive, vocal, aware and independent IRB that the research protection process can work effectively.

However, this was not a unique example. Many within the research community are unlikely to look upon research participants as "us," but more likely as "them". A quote from Albert Schweitzer $(1965$, p. 9) is a gem in this regard: "The first step in the evolution of ethics is a sense of solidarity with other human beings." Sociologists similarly often speak of the need to become the other to truly understand a situation. In this vein, when I hear about some advocacy organization or individual being too extreme in their promotion of participants' rights and safety, I am reminded of Richard Rorty's Contingency, Irony, and Solidarity (Rorty, 1989), and of its review by George Scialabba (1989) in which he discusses one of Rorty's main themes, that philosophy and ideology alone make nothing happen: they are politically useless. "Progress depends rather on extending our imaginative range ... identifying with those who are unnecessarily suffering" (Scialabba, 1989, p. 686). Scialabba relates that this process of extending the imaginative range is one for storytellers, such as journalists and novelists. For example, about George Orwell, who was a focal point in Rorty's book, Scialabba comments:

\footnotetext{
${ }^{1}$ Robert Nelson, message on IRB Forum listserve (formerly mcwirb) entitled "The Debate Over Exposure to Research Risk without Direct Benefit," June 21, 2001.
}

Both as a journalist and a novelist, Orwell worked on his readers' moral imagination, showing them suffering they had failed to notice and then showing them what the best, the most intelligent, of them would turn into if this moral obtuseness overwhelmed the fragile structure of liberalism. Rorty believes with Shelley, an earlier radical pragmatist, that "the great instrument of moral good is the imagination." (p. 287)

So, "the great instrument of moral good is the imagination." If we are responsible to, and more importantly, for, others, then we need to reach outside our usual sources of information to those we might not at first be able to relate to. For example, advocacy organizations and their proponents are often crucial in helping us expand our imaginative and empathetic parameters. They compel us oftentimes to cross the convenient ignorance divide.

\section{Strong Advocacy}

Bad stuff happens in this world, and those in apparent opposition to our complacent ideologies often bring a glimpse of that other reality. Personally, I wish we had more advocacy entities espousing sound research ethics and protections. For those who find advocates' sense of decorum or methods of communication too histrionic, I remind them that my experience described above is perhaps not all that unusual; I would bet there are many who have witnessed the "charming, witty and gracious person" in power become very indecorous when events do not evolve to their liking. A meek advocate would be no match for such a forceful opponent.

The research process can lead to pain and suffering by the participants involved, but I think most of us would agree that there is concomitant greater good generated by its product. Research of the highest order represents the active application of hope. Still, in an editorial in The Washington Post, Angell and Relman (2001) point out:

"Here are the facts: The pharmaceutical giants spend two or three times as much on marketing and administration as they do on R\&D [research and development], and their profits are about twice their R\&D costs. To cite a typical example, last year GlaxoSmithKline spent 37 percent of its revenues on marketing and administration and only 14 percent on $\mathrm{R} \& \mathrm{D}$, while making a 28 percent profit. Overall, the pharmaceutical industry is by far the most profitable in the United States"

This translates into billions and billions of dollars. I am not trying to debate here how the pharmaceuti- 
cal industry should spend its revenues. The point is that we are the recipients of a great deal of public relations-type information on the product side of the research equation whether we like it or not. Industry will always find ways to reach our cognitive senses with their intended messages. It is our responsibility in the research integrity and human research protection endeavor to reach beyond what is obviously apparent to a keener understanding of all sides and dimensions. We need to feel an obligation to those we represent to do all that we can to expand our imaginative range to what might be missing relative to the issues and cases we deliberate about and ultimately decide on.

Ethics begins with our reflective consideration of the effects of our contemplated actions on others. Rorty and Schweitzer would go further still and say that true ethical behavior on our parts is impossible without a feeling of identification and solidarity with those we represent and advocate for. Therein lies our end but also our beginning.

\section{Best Practices}

Three recommendations flow from the case described herein: (1) Meetings with powerful investigators and/ or funders should take place in IRB administrative offices. (2) IRB chairs and administrators need to be fire-walled from potential conflicts of interest arising not just from financial factors but from factors related to power, hierarchy, structure and control. (3) Effective ethical advocacy is best achieved through an educational emphasis on the development of empathy.

\section{Research Agenda}

While the literature in social psychology provides understanding of coercion, there is need for a better understanding of the actual applied contexts that result in coercion of those responsible for advocacy, and of factors that enable them to resist coercion. Needed are:

- Educational techniques that would improve moral imagination in realistic and positive ways as opposed to imagining far-fetched risks where there are none.

- A clearer understanding of the fluidity and permeability of the boundaries between self and other, us and them, with ethical decision-making as the ultimate byproduct.

\section{Educational Implications}

Ethical behavior and concomitant social progress are impossible without empathetic ability and altruistic concern. Education should be devoted to their development through venues such as film, literature, drama, case analysis, music, story-telling and oration.

\section{Author Note}

Correspondence may be addressed to: Daniel R. Vasgird, Director, Office of Research Compliance Services, University of Nebraska-Lincoln, 312 N. 14th St., Suite 209, P.O. Box 880408, Lincoln, NE 68588-0408, email: dvasgird2@unl.edu

\section{Author Biographical Sketch}

Dr. Daniel Vasgird is Research Compliance Services Director and Research Integrity Officer for the University of Nebraska, Lincoln. He conceived and developed a widely-used 6-segment web-based training program on Responsible Conduct of Research for the federal Office of Research Integrity and Columbia University. Formerly, he was a Lecturer at Columbia University's School of Public Health and an Assistant Professor in the Department of Preventive Medicine and Community Health at SUNY Downstate Health Sciences Center, and directed the Office for Responsible Conduct of Research for Columbia University and the Office of Research Conduct for the City University of New York.

\section{References}

Angell, M. \& Relman, A. (2001, June 20). Prescription for Profit. The Washington Post, p. A27.

Nelson, R. (2001, June 21). Message on IRB Forum listserve (formerly mowirb) entitled "The debate over exposure to research risk without direct benefit."

Rorty, R. (1989). Contingency, irony, and solidarity. Cambridge: Cambridge University Press.

Scialabba, G. (1989, December 4). Disenchantment and democracy [Review of the book Contingency, Irony and Solidarity, by Richard Rorty.]. The Nation, 685-688.

Schweitzer, A. (1965). The teaching of reverence for life. New York: Holt, Rinehart, and Winston. 